Japan. J. Med. Sci. Biol., 31, 91-103, 1978

\title{
ATTEMPTS AT ANALYSIS OF TOXICITY OF PERTUSSIS VACCINE \\ III. EFFECTS OF ENDOTOXIN ON LEUKOCYTOSIS IN MICE DUE TO LYMPHOCYTOSIS-PROMOTING FACTOR AND REFERENCE PREPARATIONS FOR DETERMINATION OF LYMPHOCYTOSIS-PROMOTING FACTOR
}

\author{
Masami KUROKAWA, Setsuji ISHIDA, Sadao ASAKaWA \\ and SABURo IWASA \\ Department of General Biologics Control, National Institute of Health, \\ Kamiosaki, Shinagawa-ku, Tokyo 141
}

(Received: September 28, 1977)

\begin{abstract}
SUMMARY: The effect of bacterial endotoxin on the change in peripheral leukocyte population in mice due to the lymphocytosis-promoting factor (LPF) was investigated. Endotoxin affected not only the total leukocyte count but also the leukocyte proportions at any observation time. Both the coefficient and the intercept of regression of the leukocytic response on dose of LPF were modified by endotoxin. Therefore, in a valid biological assay for LPF using the peripheral leukocyte count as a response, a common reference preparation available for any test materials, irrespective of presence or absence of endotoxin, will be impracticable. Two reference preparations were tentatively established, one being a vaccine and the other an LPF preparation containing little endotoxin. A unitage of LP activity was assigned to each reference preparation.

The results also showed that an LPF material to be tested for its possible effects on the lymphatic tissues or the reticuloendothelial system should be free from endotoxin.
\end{abstract}

\section{INTRODUCTION}

The mouse toxicity test or the mouse weight-gain test (Pittman, 1970) of pertussis vaccine, developed by Pittman and Cox (1965), is now being recommended in the WHO Requirements for Pertussis Vaccine (World Health Organization, 1964) and widely accepted in the world as the control test for freedom from toxicity of pertussis vaccine. The method is used also in studies on toxic substances of pertussis bacilli. The test is said to reflect the reactions in humans (Pittman, 1970).

The mouse toxicity test consists of three check points: (1) body weight recovery at the end of $72 \mathrm{hr}$, (2) body weight gain at the end of 7 days, and (3) late mortality. We have drawn the following conclusions from our experiments (Kurokawa et al., 1968). The object of the first check point was interpreted as the check for the early appearing toxicity attributable to endotoxin

黒川正身・石田説而・朝川貞雄・岩佐三郎（国立予防衛生研究所 一般検定部） 
and the heat-labile toxin (HLT), since the highest decrease in body weight of mice inoculated with a certain dose of either endotoxin or HLT or both appears early, within 1 or 2 days after inoculation of a material. On the other hand, the second and third check points were considered to be prescribed for lymphocytosis-promoting factor (LPF), the entity responsible for the "slow weight gain" and the "late death" (Pittman and Cox, 1965), since the effect of LPF on the body weight appears usually on day 3 or 4 and the death due to LPF usually occurs after 3 days (Ishida, 1968; Kurokawa et al., 1968). Thus the above method for the toxicity test may be interpreted as a method designed to check the contents of the three toxic substances by one test trial (Pittman, 1970). In this respect, the method is very convenient in routine use for quality control of pertussis vaccine preparations.

However, for analytical studies on the toxicities of pertussis vaccine or toxic substances of pertussis bacilli, such method which can determine quantitatively individual toxic substances separately seem necessary.

Though lymphocytosis is a characteristic response to LPF, a method for quantitative determination of LPF by total leukocyte count instead of lymphocyte count might be available, because the total leukocyte count reflects the size of lymphocytosis attributable to LPF. As the total leukocyte count is more practical than the differential count of lymphocytes, the Minimum Requirements for Biological Products of Japan (Ministry of Health and Welfare, 1971) adopted the former for checking for the LPF content. However, it was demonstrated (Ishida and Kurokawa, 1972a, b) that both endotoxin and HLT affected also the LPF-induced change in peripheral leukocyte population.

The present report describes the effects of endotoxin on the change in leukocyte population due to LPF and the possibility of establishing a reference material for quantitative determination of LPF using peripheral leukocyte count as a response. Assignment of unitage of the LP activity to reference preparations for use in the LPF determination was proposed.

\section{Materials ANd Methods}

LPF preparations: Partially purified preparations were obtained from supernatant of submerged culture of Bordetella pertussis strain $3779 \mathrm{~B}$ by sequential purification processes; ammonium sulfate precipitation, extraction in Tris-HCl buffer, ultracentrifugation at $100,000 \times g$, and gel filtration through Sephadex G-100 (Iwasa et al., 1968). They contained both LP- and HS-activities and little endotoxin and HLT as tested by the early appearing body weightdecreasing toxicity (Ishida, 1968) or the peripheral leukocyte-decreasing toxicity (Kurokawa et al., 1974) in mice and skin reaction in rabbits (Kurokawa, Ishida and Asakawa, 1969).

The mouse body weight-decreasing activity of an LPF preparation was sometimes expressed in terms of $\mathrm{D}_{0} \mathrm{D}_{4}$, namely the ip dose which would neither increase nor decrease the mean body weight of mice from the 2 nd to the 4 th 
day (Ishida, 1968).

Endotoxin preparation: An endotoxin preparation, WE-1, extracted from Escherichia coli 0-111 by the phenol-water method (Westphal and Jann, 1965) was used. Its biological activities were described in previous papers (Ishida, 1968; Kurokawa et al., 1974).

In the present experiment, doses of endotoxin to be inoculated into a mouse were selected on the basis of our previous data. The average endotoxin content of most commercial products of diphtheria-pertussis- or diphtheria-pertussistetanus combined vaccines in Japan was roughly estimated to be equivalent to $50 \mu \mathrm{g}$ of WE-1 per $\mathrm{ml}$, though the individual values distributed over a fairly wide range (Kurokawa et al., unpublished data).

Reference pertussis vaccine: A diphtheria-pertussis-tetanus combined (DPT) vaccine, P76, was selected as a reference preparation for the toxicity test of pertussis vaccine. The endotoxin content of P76 was estimated to be approximately twice as much as the mean endotoxin content of recent Japanese DPT vaccines and LP and $H S$ activities were nearly the highest among them. The HS activity of this vaccine was estimated to be $5 \mathrm{HSU} / \mathrm{ml}$ based on comparative tests with the Netherlands Reference Pertussis Vaccine (Ishida, Kurokawa and Asakawa, 1976*). We tentatively assigned one LPUv** (lymphocytosis-promoting unit) as the amount of P76 equivalent to one HSU.

Chemicals: Seven per cent cethyltrimethyl ammonium chloride-glacial acetic acid solution (CAC) was used for electronic cell counting. For electronic cell sizing $2 \%$ saponin-alcohol solution (SAS) was used. Details of the chemicals were described in a separate paper (Kurokawa et al., 1974).

Mouse: About 4-week-old femal mice of a random-bred stock (ddy/S) were used. They showed regular body-weight gain during a quarantine period after purchase from a breeder. Mice were randomly allotted to groups of five mice each. Each group was kept in a cage and assigned at random for a material, a dose of a material, and a date of bleeding, unless otherwise described.

Injection of materials and examination of peripheral leukocytes: Dilution of toxic materials was made in physiological saline solution and a $0.5-\mathrm{ml}$ portion was injected intraperitoneally.

The methods for counting and sizing peripheral leukocytes were detailed elsewhere (Kurokawa et al., 1974). Briefly, a 0.01-ml portion of blood was taken from the tail vein with a micropipette at the stated time after inoculation of the material and added to $10 \mathrm{ml}$ of Millipore-filtered saline to make a blood

* In this report the calculation of HSU was made taking HSU of the Netherlands Reference Pertussis Vaccine to be 3 instead of 4.4 per $\mathrm{ml}$ by mistake. Therefore, all the values of HSU presented in this report should be corrected.

** The unitage of LPF proposed by Sato and Arai (1972) was not accepted, because it is a kind of "absolute potency" (Maaløe and Jerne, 1952) or "absolute unit" (Miles, 1949; Gaddum, 1953).

In order to avoid possible confusion the LPU assigned for the reference vaccine, $P 76$, is referred to as LPUv hereafter. The LPU assigned for a reference LPF preparation will be referred to as LPUp (see p. 101). 
cell suspension. To the blood cell suspension $0.1 \mathrm{ml}$ of CAC or $0.3 \mathrm{ml}$ of SAS was added. A Coulter counter Model B (Coulter Electronics Inc., St. Hialeah, FLA.) was used for leukocyte counting and sizing made within 30 min after addition of CAC or SAS.

Microscopical examinations of peripheral leukocytes were made on Giemsastained smears. Three-hundred cells were examined to be sorted into granulocytes, small lymphocytes and other larger cells including monocytes, mediumand large lymphocytes.

Statistical analyses: Logarithmically transformed cell count was used as a metameter for the statistical analyses since cumulative percentage frequency was fairly linear when plotted against log cell count on a normal probability paper (Ishida and Kurokawa, 1971; Sato and Arai, 1972), while the frequency deviated clearly from a linearity before the transformation (Ishida and Kurokawa, 1971). Deviations from variance homoscedasticity were insignificant only after the logarithmic transformation. The validity tests were performed by the parallel line assay method (Finney, 1964). All significant tests were made at a probability $\mathrm{p}=0.05$ and all confidence intervals were estimated for this probability, unless otherwise specified.

\section{RESULTS \\ Effect of Endotoxin on the LPF-induced Change of Peripheral Leukocyte Population}

After inoculation of $0.5 \mathrm{ml}$ of a mixture containing $0.7 \mu \mathrm{g}$ or $1 \mathrm{D}_{0} \mathrm{D}_{4}$ of an LPF preparation, A-1, and $50 \mu \mathrm{g}$ of WE-1, daily change in number of peripheral leukocytes was followed. Two control groups were each inoculated with $0.7 \mu \mathrm{g}$ of A-1 and $50 \mu \mathrm{g}$ of WE-1, and the leukocyte count was made in the same manner. As shown in Fig. 1, some effects of endotoxin on the leukocytic response of the mouse to LPF were demonstrated. An enhancing effect of endotoxin on the total peripheral leukocyte count due to LPF was clearly observed already on day 2. A rather suppressive effect of endotoxin on the leukocyte count was often demonstrated on day 1 , as shown in Fig. 3.

As an example of microscopical examinations, peripheral leukocyte populations and total leukocyte count, obtained on day 2 are summarized in Table I. The increase in the LPF-induced leukocyte count by endotoxin appeared to be attributable almost, if not exclusively, to neutrophils.

Electric sizing was also performed on peripheral leukocytes of other groups of mice. Figure 2 is an example, in which mice were inoculated with $0.5 \mu \mathrm{g}$ of an LPF preparation, R-4, or a mixture of $0.5 \mu \mathrm{g}$ of $\mathrm{R}-4$ and $100 \mu \mathrm{g}$ of WE-1 and the leukocyte sizing was performed on day 4 . Inoculation of endotoxin with LPF resulted in a decrease in the frequency of small-sized cells and in the appearance of the second peak in the region of large-sized cells, which was considered to consist mainly of medium- and large-sized lymphocytes and 


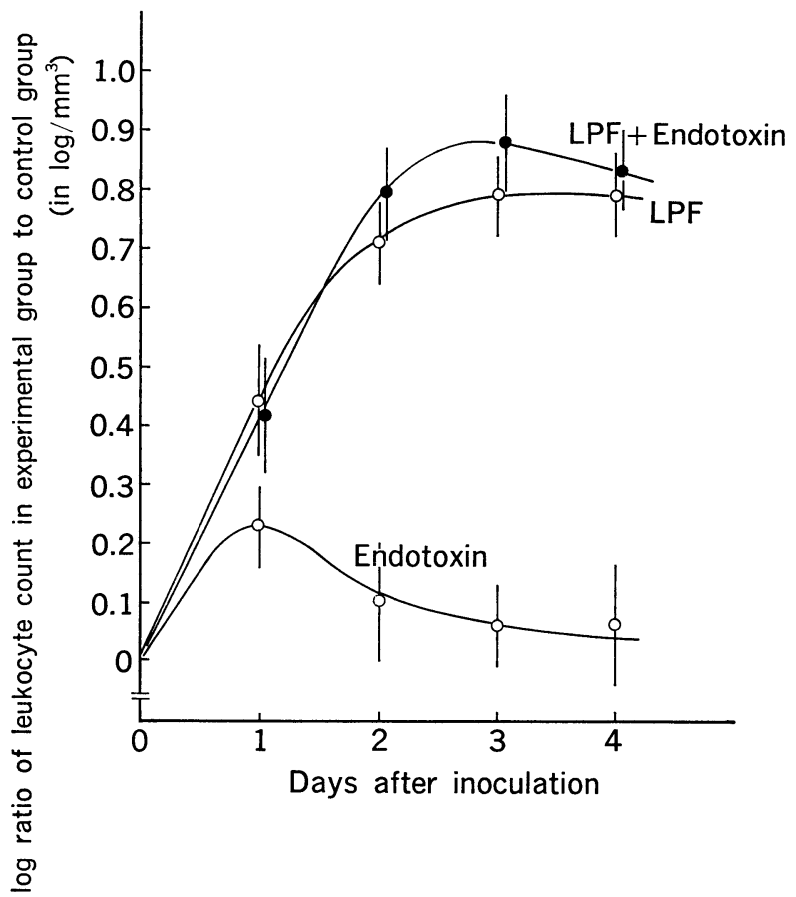

Fig. 1. Effect of endotoxin on the peripheral leukocytic response to LPF.

LPF: A-1, $0.7 \mu \mathrm{g}(O)$, Endotoxin: WE-1, $50 \mu \mathrm{g}(O)$, LPF + Endotoxin: A-1, $0.7 \mu+$ WE-1, $50 \mu \mathrm{g}(\mathrm{O})$.

Each circle represents the mean of 5 mice and the vertical line the confidence interval of the mean.

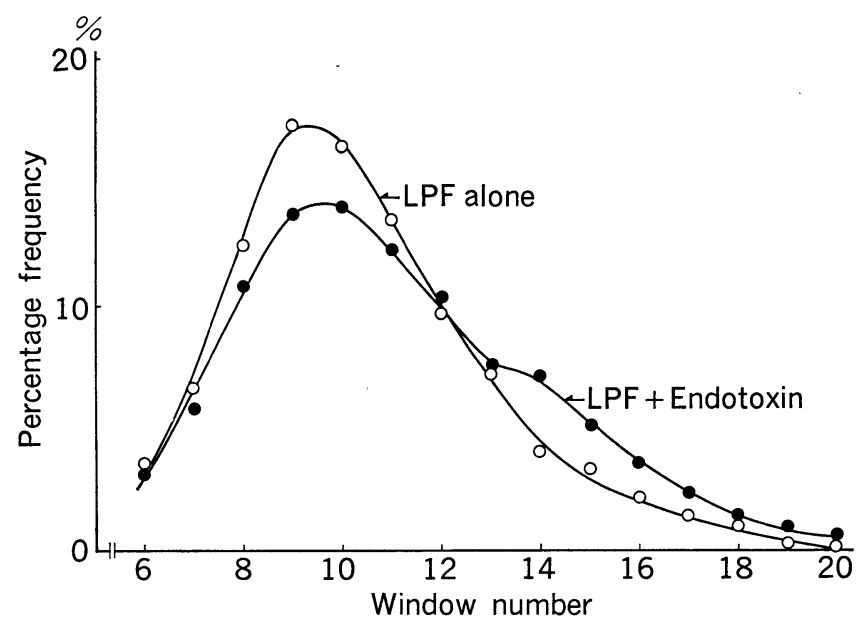

Fig. 2. Size distribution of peripheral leukocytes in mice 4 days after inoculation of LPF or a mixture of LPF and endotoxin.

LPF: R-4, $0.5 \mu \mathrm{g}(\mathrm{O})$, LPF + Endotoxin: R-4, $0.5 \mu \mathrm{g}+\mathrm{WE}-1,100 \mu \mathrm{g}(\bullet)$.

For the method for cell sizing see the text. Each circle represents the mean of 10 mice. 
TABLE I

Microscopical examination of peripheral leukocyte population and total leukocyte count 2 days after inoculation of the materials

\begin{tabular}{|c|c|c|c|c|c|c|c|}
\hline \multirow{2}{*}{\begin{tabular}{l}
\multicolumn{1}{c}{ Substance } \\
(Preparation, \\
dose per mouse)
\end{tabular}} & & \multicolumn{2}{|c|}{ Neutrophils } & \multicolumn{2}{|c|}{$\begin{array}{c}\text { Small } \\
\text { lymphocytes }\end{array}$} & \multirow{2}{*}{$\begin{array}{l}\text { Monocytes } \\
\text { and } \\
\text { large } \\
\text { lymphocytes }\end{array}$} & \multirow{2}{*}{$\begin{array}{l}\text { Total } \\
\text { leukocyte } \\
\text { count } \\
\text { (c) }\end{array}$} \\
\hline & & (a) & $\frac{c \times a}{100}$ & (b) & $\frac{c \times b}{100}$ & & \\
\hline \multirow{5}{*}{$\begin{array}{l}\text { LPF } \\
(\mathrm{A}-1,0.7 \mu \mathrm{g})\end{array}$} & & $\%$ & $\times 100 / \mathrm{mm}^{3}$ & $\%$ & $\times 100 / \mathrm{mm}^{3}$ & $\% \times 1$ & $100 / \mathrm{mm}^{3}$ \\
\hline & & 15.6 & 76.6 & 82.4 & 404.6 & 2.0 & 491 \\
\hline & & 10.5 & 42.9 & 89.5 & 366.1 & 0.0 & 409 \\
\hline & & 15.7 & 89.0 & 81.8 & 459.8 & 3.2 & 567 \\
\hline & Mean & 13.9 & 68.0 & 84.3 & 410.2 & 1.7 & 489 \\
\hline \multirow{4}{*}{$\begin{array}{l}\text { LPF }(\mathrm{A}-1,0.7 \mu \mathrm{g}) \\
+ \text { Endotoxin } \\
\quad(\mathrm{WE}-1,50 \mu \mathrm{g})\end{array}$} & & 18.9 & 78.4 & 79.4 & 329.5 & 1.7 & 415 \\
\hline & & 20.7 & 123.2 & 77.0 & 458.2 & 2.3 & 595 \\
\hline & & 23.3 & 134.2 & 74.8 & 430.8 & 1.9 & 576 \\
\hline & Mean & 21.0 & 110.1 & 77.1 & 406.2 & 2.0 & 529 \\
\hline \multirow{4}{*}{$\begin{array}{l}\text { Endotoxin } \\
(\mathrm{WE}-1,50 \mu \mathrm{g})\end{array}$} & & 15.9 & & 78.0 & & 6.1 & 94 \\
\hline & & 14.3 & & 77.6 & & 8.1 & 107 \\
\hline & & 16.7 & & 79.8 & & 3.5 & 104 \\
\hline & Mean & 15.6 & & 78.5 & & 5.9 & 102 \\
\hline \multirow[t]{4}{*}{ Saline } & & 16.5 & & 79.5 & & 4.0 & 75 \\
\hline & & 7.0 & & 88.0 & & 5.0 & 79 \\
\hline & & 16.8 & & 75.6 & & 7.6 & 111 \\
\hline & Mean & 13.4 & & 81.0 & & 5.5 & 88 \\
\hline
\end{tabular}

granulocytes.

Each of three mixtures containing a constant dose of WE-1 and graded doses of R-4 was injected into four groups of five mice and the mice of each group were bled from the tail vein for peripheral leukocyte count on day 1, 2, 3 or 4 . The mouse was used only once for the test. Mice inoculated with the corresponding doses of LPF alone were also investigated in parallel.

Daily changes in the regression line in mice inoculated with LPF alone or with endotoxin are illustrated in Fig. 3 and the regression analyses of the data in Tables II and III. None of the regressions of log number of leukocytes on log dose showed any significant deviation from linearity, as shown in Table II, within the present dose range. By addition of endotoxin, however, the position of the regression lines on days 2, 3 and 4, moved upward, whereas that on day 1 downward, though the difference in the position between the two regression lines in each pair was not always significant (Table II).

There were only a little differences in the regression coefficients between days 3 and 4, whether endotoxin was present or not (Table III). The regression coefficient on day 1 was the lowest among the four dose-response regression lines. It was suggested that the addition of endotoxin affected the regression coefficient, though the values did not significantly differ from each other in the respective 
TABLE II

Regression analysis for the data of Fig. 3

\begin{tabular}{lcccc}
\hline $\begin{array}{l}\text { On day 1 } \\
\text { Nature of variation }\end{array}$ & SS & DF & MS & F \\
\hline Preparation & 0.0984 & 1 & 0.0984 & $10.74^{* *}$ \\
Regression & 0.1330 & 1 & 0.1330 & $14.53^{* *}$ \\
Parallelism & 0.0005 & 1 & 0.0005 & 0.05 \\
Linearity & 0.0459 & 2 & 0.0230 & 2.51 \\
\hline Between doses & 0.2778 & 5 & 0.0556 & \\
Error & 0.2198 & 24 & 0.0092 & \\
\hline Total & 0.4976 & 29 & &
\end{tabular}

On day 2

\begin{tabular}{lcccc} 
Nature of variation & SS & DF & MS & F \\
\hline Preparation & 0.0139 & 1 & 0.0139 & 1.72 \\
Regression & 0.6480 & 1 & 0.6480 & $80.20^{* *}$ \\
Parallelism & 0.0163 & 1 & 0.0163 & 2.01 \\
Linearity & 0.0096 & 2 & 0.0048 & 0.59 \\
\hline Between doses & 0.6877 & 5 & 0.1375 & \\
Error & 0.1858 & 23 & 0.0081 & \\
\hline Total & 0.8736 & 28 & &
\end{tabular}

On day 3

\begin{tabular}{lcccc} 
Nature of variation & SS & DF & MS & F \\
\hline Preparation & 0.0102 & 1 & 0.0102 & 4.21 \\
Regression & 0.7001 & 1 & 0.7001 & $82.82^{* *}$ \\
Parallelism & 0.0031 & 1 & 0.0031 & 0.37 \\
Linearity & 0.0291 & 2 & 0.0146 & 1.72 \\
\hline Between doses & 0.7425 & 5 & 0.1485 & \\
Error & 0.1860 & 22 & 0.0085 & \\
\hline Total & 0.9285 & 27 & &
\end{tabular}

On day 4

\begin{tabular}{lcccc} 
Nature of variation & SS & DF & MS & F \\
\hline Preparation & 0.0233 & 1 & 0.0233 & $5.91^{*}$ \\
Regression & 0.9981 & 1 & 0.9981 & $253.21^{* *}$ \\
Parallelism & 0.0089 & 1 & 0.0089 & 2.25 \\
Linearity & 0.0089 & 2 & 0.0045 & 1.13 \\
\hline Between doses & 1.0392 & 5 & 0.2078 & \\
Error & 0.0828 & 21 & 0.0039 & \\
\hline Total & 1.1219 & 26 & & \\
\hline
\end{tabular}

* Significant at a probability $\mathrm{p}=0.05$

** Significant at a probability $\mathrm{p}=0.01$ 


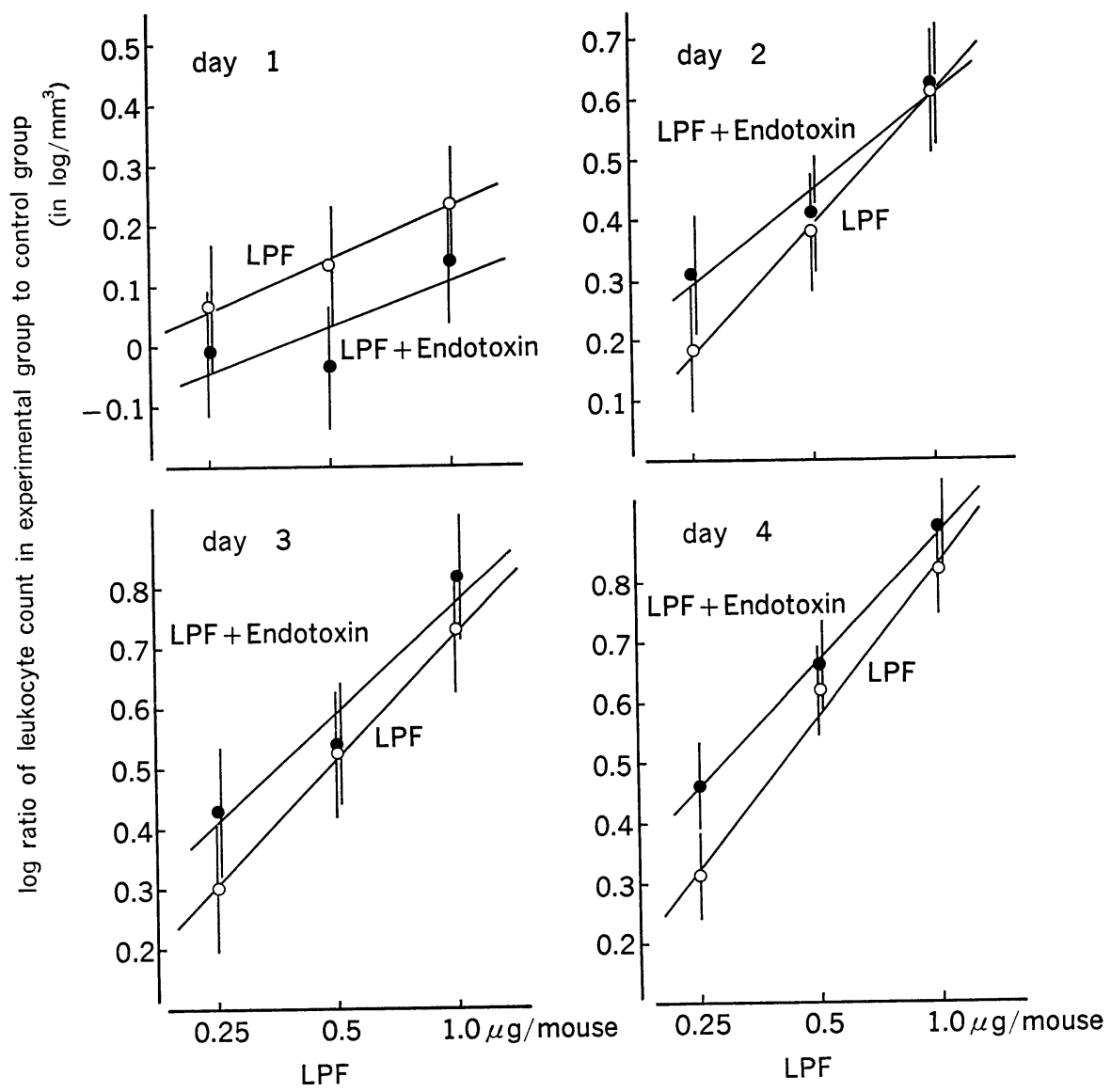

Fig. 3. Effect of endotoxin on the regression of leukocyte count on dose of LPF.

LPF: R-4, $0.25,0.5$ or $1.0 \mu \mathrm{g}$, Endotoxin: WE-1, $50 \mu \mathrm{g}$. See the legend for Fig. 1 .

\section{TABLE III}

Regression coefficient and variance for the data of Fig. 3

\begin{tabular}{cccccc}
\hline \multirow{2}{*}{$\begin{array}{c}\text { Days after } \\
\text { inoculation }\end{array}$} & \multicolumn{2}{c}{ Regression coefficient } & & \multicolumn{2}{c}{ Variance for each dose } \\
\cline { 2 - 3 } \cline { 5 - 6 } & LPF & $\begin{array}{c}\text { LPF }+ \\
\text { Endotoxin }\end{array}$ & LPF & LPF + Endotoxin \\
\hline 1 & 0.287 & 0.255 & $0.0065,0.0043,0.0065$ & $0.0265,0.0078,0.0034$ \\
2 & 0.707 & 0.512 & & $0.0048,0.0066,0.0046$ & $0.0071,0.0094,0.0186$ \\
3 & 0.700 & 0.611 & & $0.0040,0.0202,0.0065$ & $0.0075,0.0021,0.0121$ \\
4 & 0.854 & 0.704 & & $0.0014,0.0047,0.0072$ & $0.0067,0.0004,0.0027$ \\
\hline
\end{tabular}

pairs in these experiments. This suggestion, however, was substantiated in other experiments, one of which will be presented later.

The addition of endotoxin seemed not to affect the variance (Table III). 
TABLE IV

Precision index for the data of Fig. 3

\begin{tabular}{ccc}
\hline \multirow{2}{*}{$\begin{array}{c}\text { Days after } \\
\text { inoculation }\end{array}$} & \multicolumn{2}{c}{$\lambda=\mathrm{s} / \mathrm{b}$} \\
\cline { 2 - 3 } & LPF & LPF + Endotoxin \\
\hline 1 & 0.265 & 0.440 \\
2 & 0.103 & 0.206 \\
3 & 0.144 & 0.135 \\
4 & 0.078 & 0.087 \\
\hline
\end{tabular}

TABLE V

Test for parallelism among 5 dose-response lines for 3 preparations of LPF, regression coefficient for each experiment and variance for each dose

\begin{tabular}{lcccc}
\hline Nature of variation & SS & DF & MS & F \\
\hline Parallelism & 0.0483 & 4 & 0.0120 & 0.98 \\
Error & 0.7850 & 64 & 0.0122 & \\
\hline Total & 0.8333 & 68 & & \\
\hline
\end{tabular}

The response was measured on day 3.

\begin{tabular}{ccccl}
\hline Experiment & Preparation & $\begin{array}{c}\text { Regression } \\
\text { coefficient }\end{array}$ & \multicolumn{1}{l}{ Variance for each dose } \\
\hline 1 & Pr-1 & 0.633 & $0.0238,0.0247,0.0061,0.0806,0.0334$ \\
2 & $\mathrm{~A}-1$ & 0.469 & $0.0024,0.0070,0.0012,0.0032$ \\
3 &, & 0.444 & $0.0088,0.0093,0.0030$ \\
4 & $\mathrm{R}-4$ & 0.603 & $0.0061,0.0040,0.0202,0.0065$ \\
5 &,$\quad$ & 0.555 & $0.0235,0.0076,0.0131$ \\
\hline Common & 0.559 & 0.0122 \\
Test for variance homogeneity (Bartlett's test) \\
$\chi^{2}=26.67<\chi^{2}[18](0.05)=28.9$
\end{tabular}

A factor of precision of titration, $\lambda=s / b$, where $s$ is square root of variance, or standard deviation, and b regression coefficient, is shown in Table IV. There were little differences in the index among days 2, 3 and 4, while the index on day 1 was the largest.

Table V presents regression analysis of the data obtained in this laboratory with three different preparations of LPF. The leukocyte count was made on day 3. There was no indication of deviations from parallelism of the doseleukocytic response regressions among the LPF preparations. Inter-dose variances were not significantly large, though the variances varied from one experiment to another.

With the vaccines used up to this time, no significant deviations from the parallelism of the regression lines among pertussis vaccines have been suggested, though the data are not presented here. Therefore the parallel line assay method may be applied to the estimation of LPF content or LP activity of pertussis 


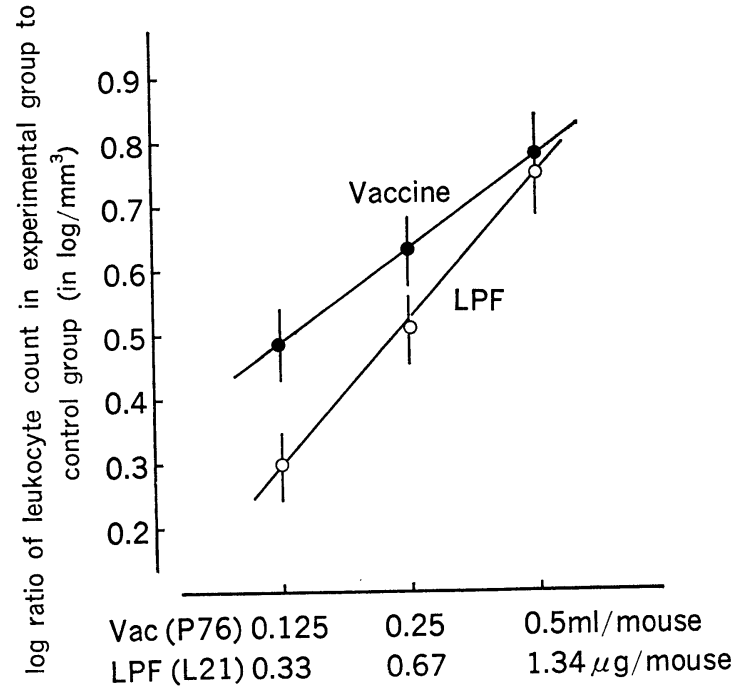

Fig. 4. Regression lines of the candidate reference preparations 4 days after inoculation. Each circle represents the mean of 10 mice and the vertical line its confidence interval.

TABLE VI

Regression analysis for the data in Fig. 4

\begin{tabular}{lcrcr}
\hline Nature of Variation & SS & DF & MS & \multicolumn{1}{c}{ F } \\
\hline Preparation & 0.2085 & 1 & 0.2085 & $29.08^{* *}$ \\
Regression & 1.3820 & 1 & 1.3820 & $192.77^{* *}$ \\
Parallelism & 0.0636 & 1 & 0.0636 & $8.87^{* *}$ \\
Linearity & 0.0019 & 2 & 0.0010 & 0.13 \\
\hline Between doses & 1.6560 & 5 & 0.3312 & \\
Error & 0.3728 & 52 & 0.0072 & \\
\hline Total & 2.0288 & 57 & &
\end{tabular}

** Significant at a probability $\mathrm{p}=0.01$

vaccines containing endotoxin at concentrations within a certain range. On the other hand, as a common regression coefficient for the data of vaccines was fairly smaller than that for the data of Table V, probably due to the presence of endotoxin, the reference vaccine may not be used for the estimation of LPF in an LPF preparation containing little endotoxin by means of the parallel-line assay method.

Then a candidate reference LPF preparation, L21, containing little or no endotoxin and the reference vaccine, P76, were tested several times especially for the parallelism between them. An example is presented in Fig. 4 and Table VI. The regression lines of P76 were not parallel with those of L21 without exception as expected from the previous results. This observation indicated that the use of a common reference preparation, irrespective of presence or 
absence of endotoxin, will be impractical for estimation of LPF content in test materials. There has been no authorized way to standardize a candidate reference based on comparative experiments with another reference preparation, when the regression lines of the two preparations were significantly deviated from parallelism. We were obliged to assign tentatively a unitage for an amount of L21 having shown an equivalent LP activity to that produced by one LPUv of P76. One milliliter of L21 was defined as 21 LPUp*.

\section{Discussion}

The data suggested the applicability of the parallel line assay method for quantitative determination of LP activity of pertussis vaccines on the basis of total peripheral leukocyte count. The determination may be possible any time between 1 and 4 days after inoculation of the material. However, on account of a higher precision of estimation, counts on day 3 or 4 may be preferable to that on day 1.

Endotoxin, when contained at a certain concentration in the material, clearly affected the peripheral leukocyte count increased by LPF on any observation day and changed both the coefficient and the intercept of the regression line. The effect of endotoxin on a precise estimation of LPF was usually too large to be neglected.

A countermeasure to overcome such an effect of endotoxin contamination may be the use of a material containing a known amount of LPF and of endotoxin as a reference preparation. However, as the endotoxin content of pertussis vaccine prepared in a usual manner to meet the toxicity tests of Japanese Requirements extended over a fairly wide range (Kurokawa et al., unpublished data), the desirable content of endotoxin in the reference vaccine will be difficult to choose. We established tentatively two reference preparations. One was a vaccine, of which endotoxin content was estimated to be somewhat higher than the average concentration of current Japanese pertussis vaccines while LP- and HS activities were almost highest among them. The other was an LPF preparation containing little endotoxin. It may be reconsidered whether some other reference preparations are necessary for a material containing endotoxin at a lower concentration than the reference vaccine.

Endotoxin has complicated effects on lymphatic organs. The effect dealt with in this report is one of such manifestations. Therefore, LPF preparations to be tested for the effect of LPF on the lymphatic tissues should be free from endotoxin.

HLT was found to induce characteristic leukocytosis (Ishida and Kurokawa, 1972b). Therefore it may also affect the total increased leukocyte count due to LPF. However, as HLT, unlike LPF, is easily destroyed by mild heating, the effect of HLT possibly contained by a material on LPF assay can be eliminated by preheating.

* See p. 93. 
Though it has remained unsettled whether or not LPF and histaminesensitizing factor (HSF) are borne by different substances, the term "LPF" was dealt with as if it was a factor different from HSF in the present paper for convenience' sake. In any case, respective methods for precise quantification of LP and HS activities are indispensable in order to resolve whether or not LP and HS activities are different functions of the same substance. A method for estimation of HS activity with a sensitivity comparable to that of the present method for LPF will be proposed in a separate paper.

\section{REFERENCES}

Chervenick, P. A., Boggs, D. R., Marsh, J. C., Cartwright, G. E. and Wintrobe, M. M. (1968): Quantitative studies of blood and bone marrow neutrophils in normal mice. Am. J. Physiol., 215, 353-360.

Dor, M., NAKase, Y. ANd Kasuga, T. (1972): Separation and purification of histamine-sensitizing factor of Bordetella pertussis. Japan. J. Bacteriol., 27, 307 (in Japanese).

Finney, D. J. (1964): Statistical Method in Biological Assay. 2nd ed., Charels Griffin, London.

Gaddum, J. H. (1953): Bioassays and mathematics. Pharmacol. Rev., 5, 87-134.

Homma, R., Kuratsuka, K., Shimazaki, Y. and Funasaka, I. (1970): The partial purification and some biological activities of histamine sensitizing factor from Bordetella-pertussis. Japan. J. Med. Sci. Biol., 23, 277-281.

IsHIDA, S. (1968): Characterization of the body weight-decreasing toxicities in mice by the lymphocytosis-promoting factor and the heat-labile toxin of $B$. pertussis and endotoxin. Japan J. Med. Sci. Biol., 21, 115-135.

IshidA, S. AND KurokAwA, M. (1971): Determination of lymphocytosis-promoting factor. Medicine and Biology, 83, 117-122 (in Japanese).

IshidA, S. AND KUROKAWA, M. (1972a): Influence of endotoxin on lymphocytosis. Medicine and Biology, 84, 219-223 (in Japanese).

IsHIDA, S. AND KuRoKAwA, M. (1972b): Effects of heat-labile toxin of B. pertussis in mouse blood cells, with special reference to the determination of LPF. Medicine and Biology, 84, 255-259 (in Japanese).

Ishida, S., KurokAwa, M. AND Asakawa, S. (1976): A new biological assay method for histaminesensitizing factor using survival time as a response. Japan. J. Med. Sci. Biol., 29, 139-150.

Iwasa, S., Ishida, S., Asakawa, S. ANd Kurokawa, M. (1968): Lymphocytosis-promoting factor produced by Bordetella pertussis. Japan. J. Med. Sci. Biol., 21, 363-368.

Iwasa, S., Kurokawa, M. AND Izumi, N. (1972): Lymphocytosis-promoting factor produced by Bordetella pertussis. Japan. J. Bacteriol., 27, 305 (in Japanese).

Kurokawa, M., Ishida, S. AND Asakawa, S. (1969): Attempts at analysis of toxicity of pertussis vaccine. II. Quantitative determination of the heat-labile toxin by skin reaction. Japan. J. Med. Sci. Biol., 22, 293-307.

Kurokawa, M., Ishida, S., Iwasa, S., Asakawa, S. And Kuratsuka, K. (1968): Attempts at analysis of toxicity of pertussis vaccine. I. Body weight-decreasing toxicity in mice. Japan. J. Med. Sci. Biol., 21, 137-153.

Kurokawa, M., Ishida, S., Goto, N. And Kuratsuka, K. (1974): A new method for biological assay of endotoxin using change in peripheral leukocyte population in mice as a response. Japan. J. Med. Sci. Biol., 27, 173-189.

MaAl $\varnothing$ E, O. And Jerne, N. K. (1952): The standardization of immunological substances. Ann. Rev. Microbiol., 6, 349-366.

Miles, A. A. (1949): The biological unit of activity. Bull. WHO, 2, 205-213.

Pittman, M. And Cox, C. B. (1965): Pertussis vaccine testing for freedom from toxicity. Appl. Microbiol., 13, 447-456.

PrtTman, M. (1970): Bordetella pertussis-Bacterial and host factors in the pathogenesis and prevention of whooping cough. p. 239-270. In S. MudD (ed.), Infections Agents and Host Reaction, Saunders, Philadelphia. 
Sato, Y. ANd AraI, H. (1972): Leucocytosis-promoting factor of Bordetella pertussis. I. Purification and characterization. Infect. Immun., 6, 899-904.

Westphal, O. AND JANN, K. (1965): Bacterial lipopolysaccharides. Extraction with phenol-water and further applications of the procedure. p. 83-91. In R. L. Whistler, J. N. Be-MilleR and M. L. Wolfrom (ed.), Methods in Carbohydrate Chemistry, Vol. V, Academic Press, New York.

World Health Organization (1964): Requirements for Pertussis Vaccine. WHO techn. Rep. Ser., No. 274, 25-40. 